\title{
EBSD: a powerful microstructure analysis technique in the field of solidification
}

\author{
E. BOEHM-COURJAULT, F. GONZALES, A. JACOT, \\ F. KOHLER*, A. MARIAUX, C. NIEDERBERGER †, \\ M.A. SALGADO-ORDORICA \& M. RAPPAZ \\ Computational Materials Laboratory, Ecole Polytechnique Fédérale de Lausanne, STI-IMX-LSMX, \\ Station 12, CH-1015 Lausanne, Switzerland.
}

Key words. Aluminium alloys, EBSD, OIM, peritectic copper alloys, solidification.

\section{Summary}

This paper presents a few examples of the application of electron back-scatter diffraction (EBSD) to solidification problems. For directionally solidified Al-Zn samples, this technique could reveal the change in dendrite growth directions from $<100>$ to $<110>$ as the composition of zinc increases from 5 to $90 \mathrm{wt} \%$. The corresponding texture evolution and grain selection mechanisms were also examined. Twinned dendrites that form under certain solidification conditions in $\mathrm{Al}-\mathrm{X}$ specimens (with $\mathrm{X}=\mathrm{Zn}$, $\mathrm{Mg}, \mathrm{Ni}, \mathrm{Cu}$ ) were clearly identified as $<110>$ dendrite trunks split in their centre by a (111) twin plane. In Zn-0.2 wt\% Al hot-dip galvanized coatings on steel sheets, EBSD clearly revealed the preferential basal orientation distribution of the nuclei as well as the reinforcement of this distribution by the faster growth of $<10 \underline{10}>$ dendrites. Moreover, in Al-Zn-Si coatings, misorientations as large as $10^{\circ} \mathrm{mm}^{-1}$ have been measured within individual grains. Finally, the complex band and lamellae microstructures that form in the $\mathrm{Cu}-\mathrm{Sn}$ peritectic system at low growth rate could be shown to constitute a continuous network initiated from a single nucleus. EBSD also showed that the $\alpha$ and $\beta$ phases had a Kurdjumov-Sachs crystallographic relationship.

\section{Introduction}

The electron back-scatter diffraction (EBSD) technique, also called orientation imaging microscopy (OIM) or back-scatter Kikuchi diffraction pattern (BKDP) method, is useful to determine the local crystal structure and orientation of single or polycrystals. The principles and applications of this

Correspondence to: Dr. E. Boehm-Courjault. Tel: +41216932978 ; fax: +41216 935890; e-mail: emmanuelle.boehm@epfl.ch

*Current address: ETA SA, Business Unit Mecaline, CH-2540 Grenchen, Switzerland ${ }^{\dagger}$ Current address: Laboratory for Mechanics of Materials and Nanostructures, Empa

- Materials Science \& Technology, Feuerwerkstr. 39, CH-3602 Thun, Switzerland technique have already been described in several papers (e.g. Schwartz et al., 2000; Baba-Kishi, 2002; Dingley, 2004), and will not be detailed here. Although EBSD was initially developed for the study of deformation and recrystallization mechanisms, it was applied very early to the characterization of solidified metallic alloys (Gandin et al., 1995). Indeed, several aspects of solidification can be examined with this technique: clear identification of grains, characterization of nuclei orientation distributions in the bulk or at surfaces, characterization of volumetric or surface orientation distribution, study of grain competition in columnar regions or between columnar and equiaxed zones, determination of crystallographic relationship between phases in eutectic or peritectic systems or between a phase and a surface over which it has heterogeneously nucleated, determination of dendrite growth directions and of sub-grain misorientations formed during solidification, etc.

With the intent of validating the so-called CAFE model (cellular automata-finite element) for the prediction of grain structure formation in solidification, our laboratory was among the first to apply EBSD to the characterization of columnar grains in Ni-base superalloys (Gandin et al., 1995). A few years later, Henry et al. applied this technique to an unusual dendrite morphology considered as a defect in the aluminium industry, the so-called feathery grains (Henry et al., 1997, 1998, 2004; Henry, 1999). These authors showed unambiguously that these grains were made of $<110>$ twinned dendrites split in their centre by a coherent (111) twin plane. They could also evidence the gradual misorientation occurring among successive lamellae. At about the same time, Sémoroz et al. (2001, 2002a, b) made EBSD observations in thin $\mathrm{Al}-45 \mathrm{wt} \% \mathrm{Zn}$ and $\mathrm{Zn}-0.2 \mathrm{wt} \% \mathrm{Al}$ coatings deposited on steel sheets by the hot-dipping process. In fcc coatings, $\mathrm{Al}$ dendrites were found to grow along $<320>$ directions, whereas $\mathrm{Zn}$ dendrites grew along $<10 \underline{10}>$ in hcp coatings. In both alloys, large misorientations were revealed within each grain (up to $10^{\circ} \mathrm{mm}^{-1}$ ). 
In this present overview, five examples of EBSD applications concerning the Al-Zn system are presented. They are further developments of the works cited earlier:

(1)A determination of dendrite growth directions in directionally solidified (DS) Al-Zn specimens, as a function of the zinc composition.

(2) A study of the influence of the dendrite growth direction on the texture evolution in DS samples.

(3) A study of twinned dendrites in Al-Zn that are formed in the presence of slight natural convection and under fast cooling conditions.

(4) A study of the misorientations within individual grains of Al-Zn-Si solidifying in thin coatings.

(5) A determination of the nuclei orientation distribution in Zn-Al hot-dip coatings.

Finally, the last part of this paper will show one application of EBSD to the solidification at low speed of peritectic $\mathrm{Cu}-$ Sn alloys. This technique could reveal the interconnection between the various morphologies (bands and lamellae) as well as the crystallography relationship between the primary and peritectic phases.

\section{Experiments and methods}

\section{Solidification of Al-Zn bulk specimens}

Al-Zn specimens were solidified using two methods: Bridgman solidification (BS) and directional solidification (DS). The details of both techniques are given in the paper of Gonzales and Rappaz (2006). The hot zone of the BS furnace was resistively heated by a cylindrical silicon carbide tube, whereas a water-cooled copper tube, directly inserted in the furnace, was used as a cold zone. In this way, a thermal gradient $G$ of about $100 \mathrm{~K} \mathrm{~cm}^{-1}$ was achieved. The solidification speed $v$ was fixed to $4 \mathrm{~mm} \mathrm{~min}^{-1}$. Specimens, typically $20-25 \mathrm{~cm}$ long and $5.5 \mathrm{~mm}$ final diameter, were inserted in an aluminium tube. The DS installation, adapted from the experimental setup of Henry et al. (1998), produced nearly cylindrical ingots of $55 \mathrm{~mm}$ diameter and $70 \mathrm{~mm}$ height. A cylindrical stainless steel mould (2-mm-thick wall) was closed at the bottom by a thin sheet $(0.5 \mathrm{~mm}$ thick). The inner surface of the mould was coated with a thin boron nitride film to prevent Fe contamination. Lateral insulation with thick fibreglass wool together with a heating wire ensured one-dimensional solidification conditions. After melting, the whole system was cooled with an adjustable water jet (800-3200 $\mathrm{Lin}^{-1}$ flux) installed $1 \mathrm{~cm}$ below the bottom of the mould. As measured by thermocouples, the reduced thickness of the bottom sheet and the water flux allowed having $G \cong 20-150 \mathrm{~K} \mathrm{~cm}^{-1}$ and $v \cong 0.5-2 \mathrm{~mm} \mathrm{~s}^{-1}$ just $1 \mathrm{~mm}$ above the chill plate. Each amount of zinc and aluminium was melted separately in a furnace and mixed afterwards in a crucible. The alloy was then poured in the pre-heated mould. To eliminate any forced convection in the melt, the system was allowed to rest for
$10 \mathrm{~min}$. After that, the external heating source was shut down and the water jet was started. For the production of twinned dendrites in the same specimens, natural convection was induced simply by removing the lateral thermal insulation and heating wire.

After solidification, longitudinal and transversal sections of the ingots were ground with increasingly fine $\mathrm{SiC}$ papers lubricated with water (grade 220-2400) and polished to mirror quality with 6- and 1- $\mu \mathrm{m}$ diamond spray and DPMol clothes (Struers A/S, Ballerup, Denmark) lubricated with ethanol. To remove the mechanically deformed thin surface layer and to improve contrast and indexing of the pseudoKikuchi lines in the EBSD measurement, all analysed surfaces were electropolished with an A2-Struers solution. Depending on the alloy composition and the thickness of the sample, electropolishing was performed under a voltage of 10 and 50 $V$ and during 5-10 s at room temperature. EDX measurements have shown that chemical composition is homogeneous in the whole sample.

\section{$\mathrm{Zn}-\mathrm{Al}$ and $\mathrm{Al}-\mathrm{Zn}-\mathrm{Si}$ coatings deposited on steel sheets}

$\mathrm{Zn}-\mathrm{Al}$ and $\mathrm{Al}-\mathrm{Zn}-\mathrm{Si}$ coatings are applied industrially on steel sheets for corrosion protection using a hot-dipping process. In this continuous process, the steel sheet enters into the metallic bath after chemical cleaning and pre-heating. At the exit, air knives can adjust the coating thickness (typically around $20 \mu \mathrm{m}$ ). This layer subsequently solidifies and cools down in ambient air. The composition of the layers is $\mathrm{Zn}-0.2 \mathrm{Al}$ and $\mathrm{Al}-43.4 \mathrm{Zn}-1.6 \mathrm{Si}$ (in wt\%). Industrial sheets already coated with $\mathrm{Zn}-0.2 \mathrm{wt} \% \mathrm{Al}$ were cut and placed in an infrared furnace (Ulvac Riko, Inc., Yokohama, Japan) for remelting experiments. After reaching very quickly $450^{\circ} \mathrm{C}$ in order to prevent formation of inter-metallic iron-zinc outbursts, the coated sheets were cooled down by an adjustable gas flow at cooling rates ranging from -5 to $-40 \mathrm{~K} \mathrm{~s}^{-1}$. No grinding or chemical attack was necessary to get sufficiently contrasted pseudo-Kikuchi lines for $\mathrm{Zn}-\mathrm{Al}$ coatings. By contrast, $\mathrm{Al}-\mathrm{Zn}-$ Si-coated steel sheets directly obtained from a galvanization line were characterized by EBSD. In this case, the same preparation as described in the section Solidification of $\mathrm{Al}-\mathrm{Zn}$ bulk specimens was used.

\section{Solidification of $\mathrm{Cu}-\mathrm{Sn}$ specimens}

Hypoperitectic $\mathrm{Cu}-\mathrm{Sn}$ alloys of various compositions were cast in a vacuum furnace from appropriate weights of pure $\mathrm{Cu}$ $99.99 w t \%$ and pure Sn-99.99wt\%. These alloys were then solidified in a high-gradient BS furnace made of a molybdenum susceptor surrounded by an induction coil. The furnace was separated by an adiabatic zone from a liquid metal cooling bath used for efficient heat extraction. With a temperature of $1500^{\circ} \mathrm{C}$ in the hot zone, a thermal gradient of $21 \mathrm{~K} \mathrm{~mm}^{-1}$ could be achieved in the adiabatic zone. Under such conditions, 
the two growth velocities of 0.5 and $0.58 \mu \mathrm{m} \mathrm{s}^{-1}$ used to solidify the specimens were below the critical velocity for constitutional under-cooling of individual $\alpha$ and $\beta$ phases. Specimens with a thin tubular geometry (outer diameter of $6 \mathrm{~mm}$ and inner diameter of $4 \mathrm{~mm}$ ) were used to limit natural convection induced by the lighter tin solute elements rejected at the solid-liquid interface. After solidification, longitudinal and transversal sections were ground with $\mathrm{SiC}$ papers of decreasing grit size from grade 500 to 4000 , and water as lubricant. They were then polished to mirror quality using 1 - and 0.25- $\mu \mathrm{m}$ diamond spray and DP-Nap clothes (Struers) lubricated with Struers blue lubricant. Two more polishing steps were necessary to perform the EBSD measurements and were done using a vibratory polisher (Vibromet, Buehler, Ltd., Lake Bluff, IL, U.S.A.): first, with a DP-Nap cloth and OP-U silica suspension (Struers) and last with a DP-Nap cloth and $6 \mathrm{vol} \% \mathrm{H}_{2} \mathrm{O}_{2}$-OP-S silica suspension (Struers).

\section{EBSD measurements}

The EBSD observations were done using a XL30FEG SEM microscope (Philips Electronics Instruments Corp., Mahwah, NJ, U.S.A.) equipped with a Nordlys camera (HKL Technology A/S, Hobro, Denmark). The HKL Channel 5 software (HKL Technology A/S) was used for data acquisition and treatment. Measurements were performed with these parameters: tilt of $70^{\circ}$, acceleration voltage between 20 and $25 \mathrm{kV}$, spot size 4 (few nanometres) and working distance between 20 and $25 \mathrm{~mm}$. For grain identification, a disorientation criterion of $5^{\circ}$ was used.

\section{Results and discussion}

\section{Dendrite growth directions in Al-Zn alloys}

Columnar Al-Zn dendrites obtained by DS and BS were characterized using a combination of optical microscopy observations and EBSD analyses. From about 10 dendrites having a trunk precisely aligned with the longitudinal section, an average dendrite trunk orientation was deduced. In these experiments, EBSD was used as a 'microbeam' diffraction setup: the beam stroke a single dendrite trunk that could be clearly identified as growing in the plane of the metallographic section. It was shown that $<100>$ dendrites grow in low composition alloys (below $25 \mathrm{wt} \% \mathrm{Zn}$ ), whereas <110> dendrites form beyond $60 \mathrm{wt} \%$ (Gonzales \& Rappaz, 2006). In between, a gradual dendrite orientation transition (DOT) occurs; the growth direction rotates from $<100>$ to $<110>$ in a (001) plane, as the zinc composition increases (these directions are reported in Table 1). The growth direction rotation is due to the variation of the solid-liquid interfacial energy (Gonzales \& Rappaz, 2006). At the start and end of the DOT (around 30 and $55 \mathrm{wt} \%$ ), textured seaweeds were observed instead of dendrites. Such seaweed structures were
Table 1. $<\mathrm{hkl}>$ Dendrite growth direction observed in DS and BS Al-Zn specimens as a function of the nominal composition, $\mathrm{c}_{0}, \theta$ is the angle between the $<100>$ direction and the $<\mathrm{hk} 0>$ dendrite growth direction.

\begin{tabular}{llcc}
\hline $\mathrm{c}_{0}$ & $\begin{array}{c}<\mathrm{hkl}> \\
\mathrm{wt} \%\end{array}$ & $\begin{array}{c}<\mathrm{hkl}> \\
\mathrm{BS}\end{array}$ & $\begin{array}{c}\theta \\
\text { deg. }\end{array}$ \\
\hline 5 & $<100>$ & & 0 \\
10 & $<100>$ & $<100>$ & 0 \\
25 & $<100>$ & $<100>$ & 0 \\
30 & $<310>$ & & Mean \\
& $<410>$ & & 16.2 \\
35 & $<210>$ & $<740>$ & 26.6 \\
45 & & $<320>$ & 29.8 \\
50 & $<320>$ & & 33.7 \\
55 & $<110>$ & & 45 \\
60 & $<110>$ & $<110>$ & 45 \\
75 & $<110>$ & $<110>$ & 45 \\
90 & $<110>$ & & 45 \\
\hline
\end{tabular}

previously observed by Akamatsu et al. (1995). Figure 1 summarizes the main experimental results obtained in the present study.

\section{Texture and grain selection evolution in Al-Zn DS specimens}

It is well known that in alloys where $<100>$ dendrites grow, a $<100>$ texture develops in the columnar zone. The pioneering work of Chalmers already established a link between the density of columnar grains in transverse sections, their texture and the distance from the mould wall (Chalmers, 1964). More recently, Gandin et al. (1995) have measured by EBSD the texture evolution in an Inconel X750 alloy (Inco Alloys International, Inc., Huntington, WV, U.S.A.) that was directionally solidified in a ceramic mould over a copper chill plate. Similar investigations were then done on $\mathrm{Al}-\mathrm{Zn}$ specimens of various compositions, for which $<\mathrm{hk} 0>$ dendrites form (see the section Dendrite Growth Directions in Al-Zn Alloys). For that purpose, DS specimens were cut transversely at various distances from the chill surface after solidification and analyzed using EBSD (Gonzales \& Rappaz, 2008). Figure 2 shows the result of such analyses for a typical specimen, namely, Al- $25 \mathrm{wt} \% \mathrm{Zn}$. Only one part of the sample is scanned by EBSD $(8 \times 6 \mathrm{~mm})$. The intensity dies off as a function of depth because the grain density decreases from the chill zone to the top owing to a grain growth competition (e.g. in the $\mathrm{Al}-25 \mathrm{wt} \% \mathrm{Zn}$, the grain density varies from 20 grains $\mathrm{mm}^{-2}$ at the chill zone to 3 grains $\mathrm{mm}^{-2}$ at $40 \mathrm{~mm}$ height). The EBSDreconstructed grain structure shows the grain boundaries $\left(5^{\circ}\right)$ and grain texture in a longitudinal section (top), whereas pole figures for transverse sections at various heights from the chill plate are shown at the bottom. In these figures, 

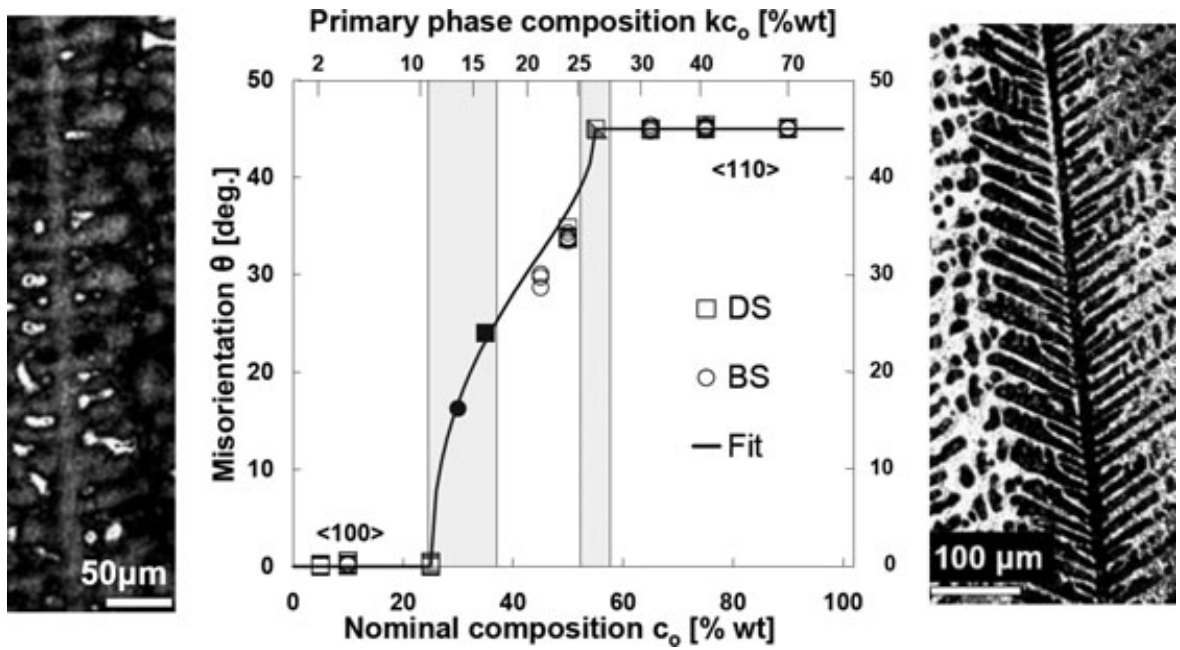

Fig. 1. Angle $\theta$ between the growth direction of the dendrite trunk (open symbols) or the texture main direction of the seaweeds (filled symbols) and the $<100>$ direction, as a function of the zinc composition in Al-Zn alloys. Light grey zones and filled symbols correspond to compositions for which textured seaweeds were observed. A $<100>$ dendrite of an Al-10wt\%Zn alloy is shown on the left, whereas a $<110>$ dendrite of an Al-90wt\%Zn alloy is displayed on the right, measurements were made at middle height of the bulk sample (After Gonzales \& Rappaz, 2006).

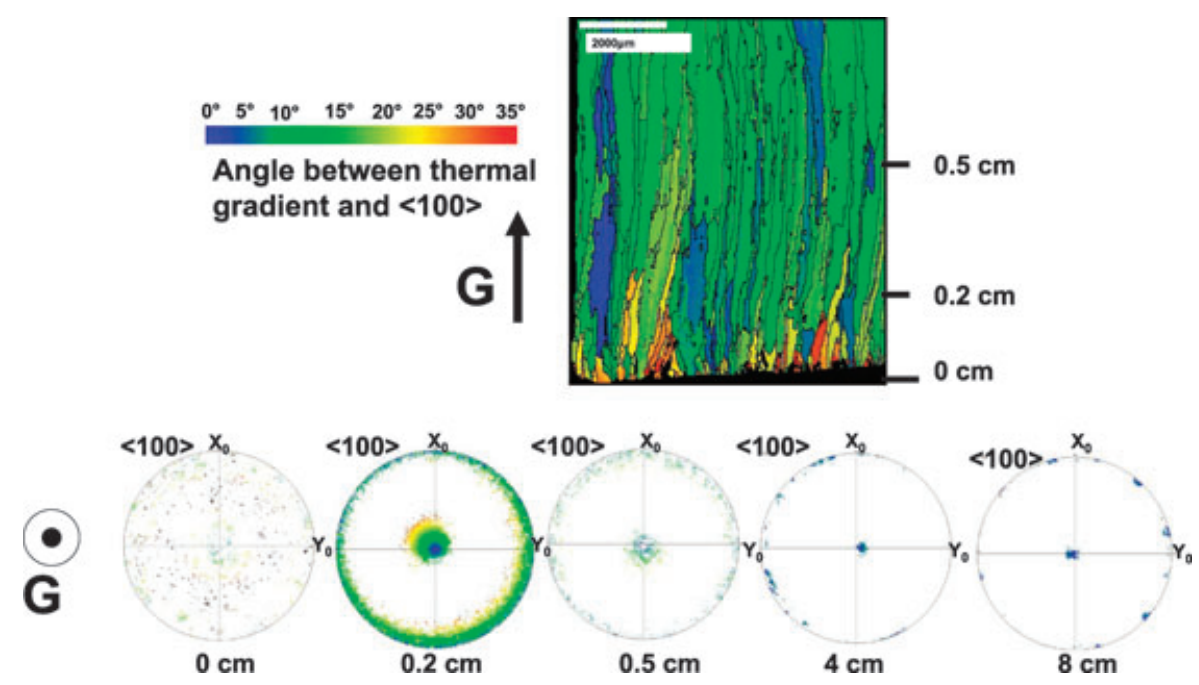

Fig. 2. Texture evolution of an Al-25wt\%Zn ingot obtained by directional solidification. The EBSD map (top) shows the grain boundaries (condition of $5^{\circ}$ of misorientation between adjacent points) and grain texture in a longitudinal section. Pole figures (bottom) are represented at different heights from the chill plate for transverse sections (after Gonzales \& Rappaz, 2008).

the thermal gradient is at the centre, and the colour code is the same as for the longitudinal section (angle between the thermal gradient and the closest $<100>$ direction for the $\mathrm{Al}-25 \mathrm{wt} \% \mathrm{Zn}$ ).

Representing such an EBSD map with grain boundaries allows revealing the macrostructure of the sample. Two specific zones are highlighted: a small layer of equiaxed grains $(600 \mu \mathrm{m})$ at the bottom of the DS specimen directly in contact with the stainless steel sheet (chill) and a columnar region made of grains elongated along the thermal gradient. Similarly to the mechanism outlined by Walton and Chalmers for $<100>$ dendrites, it was shown that a $<\mathrm{hk} 0>$ fibre texture forms in Al-Zn DS specimens as one moves away from the bottom of the ingot, regardless whether the microstructure is made of $<\mathrm{hk} 0>$ dendrites or seaweeds (see Table 1). The transition from a nearly random distribution of orientations near the chill surface to a textured structure away from it suggests that nucleation is a random process with respect to orientation, whereas growth selection is strongly orientation dependent. For seaweed structures, EBSD showed that the grain selection and the texture evolution are not as effective as for dendritic specimens. 


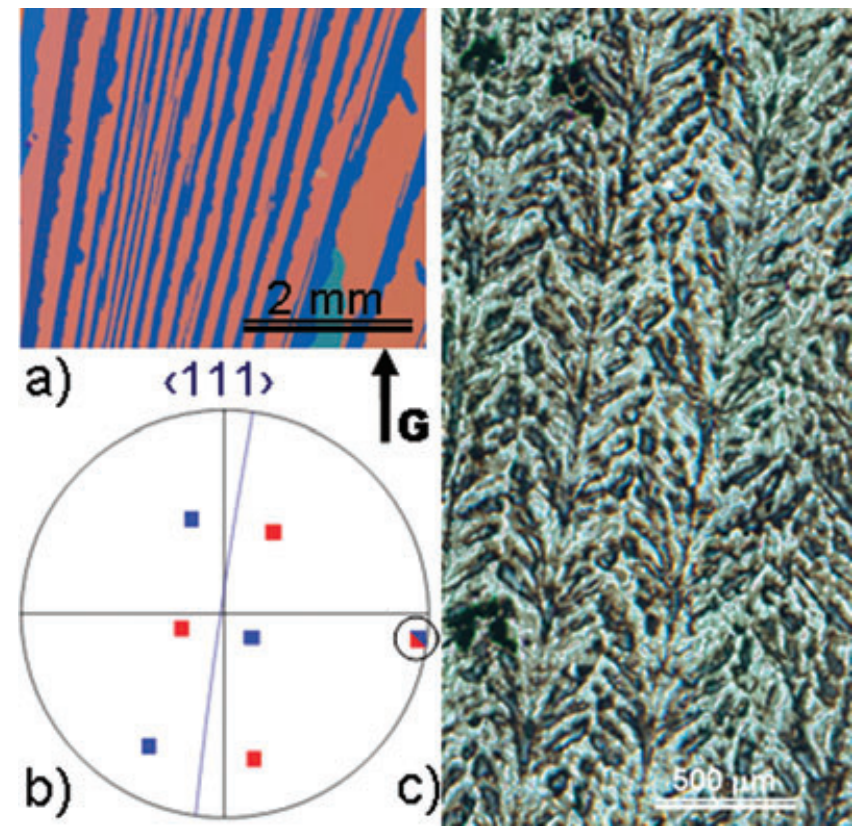

Fig. 3. (a) EBSD orientation map of a twinned single grain in an $\mathrm{Al}$ $40 \mathrm{wt} \% \mathrm{Zn}$ ingot obtained by directional solidification, (b) $<111>$ pole figure showing the common [111] direction perpendicular to the twin plane, which is projected as an arc of a circle. The average orientation of each lamella was used to draw the pole figure, (c) actual microstructure; each dendrite trunk is split by the twin plane and side arms meet along a wavy twin boundary.

\section{Twinned dendrite growth in DS Al-Zn ingots}

Under certain solidification conditions $\left(G \cong 100 \mathrm{~K} \mathrm{~cm}^{-1}\right.$, $v \cong 1 \mathrm{~mm} \mathrm{~s}^{-1}$, presence of convection), feathery grains were observed in DS Al-Zn ingots within a composition range of $10-40 w t \% Z n$. Thought to be a consequence of an atomic scale statistical defect event, the nucleation of a twin would happen at the solid-liquid interface in the early stages of solidification (Burke et al., 1988; Hoyt \& Asta, 2002) and would be stabilized by processing conditions and some slight convection in the melt (Henry et al., 2004). As recently pointed out by Henry et al. $(1997,1999)$, feathery grains are formed by a lamellar structure of alternate twinned and un-twinned regions that over-grow, as solidification goes on, regular columnar grains containing ordinary dendrites. Figure 3(a) shows an EBSD orientation map from a twinned region of an $\mathrm{Al}-40 \mathrm{wt} \% \mathrm{Zn}$ alloy whose actual microstructure can be observed in Fig. 3(c). The colour of the different elongated regions (blue and orange) in Fig. 3(a) corresponds to those of the $<111>$ pole figure shown in Fig. 3(b): each region corresponds in fact to half a dendrite of Fig. 3(c) with an average width of about $250 \mu \mathrm{m}$. The straight line separating an orange and blue region corresponds to the centre of a dendrite, whereas the more corrugated one is located at the line of impingement of secondary dendrite arms. As can be seen in the pole figure, the orange and blue regions share a common [111] direction, whereas the other three $<111>$ directions are in perfect symmetry relationship with respect to the common (111) plane. This shows the twin relationship between the two halves of each dendrite, with a coherent (111) twin plane at the centre of their trunk and an incoherent (111) twin boundary at the region of impingement of secondary arms.

The gradual rotation of the blue-orange, twinned-untwinned regions shown in Fig. 3(a), that is, progressive inclination with respect to the thermal gradient, $G$, reveals the misorientation occurring between twinned dendrites during their growth (only the average orientation is shown in Fig. 3(b)). More detailed EBSD maps revealed that a misorientation of about $0.5^{\circ}$ is present between two successive twinned dendrites (Henry et al., 1997, 1998). However, this is not visible in Fig. 3(a).

To propagate the twin plane, the twinned dendrite growth direction must be contained within the plane itself. In fact, there was some confusion in past studies between $<112>$ and $<110>$ dendrite growth directions (Eady \& Hogan, 1974). This problem arose mainly as a confusion between the real dendrite growth direction and the mean orientation of a feathery grain along the thermal gradient. As a matter of fact, twinned dendrites can be quite misoriented with respect to the thermal gradient as can be seen in Fig. 3(a). To avoid misleading measurements, the orientation of the twin plane can be determined precisely with respect to the specimen axes using EBSD. After making precise cuts parallel to this plane, the trunk direction can be identified: it was found to always correspond to a $<110>$ direction, regardless of the solute element $(\mathrm{Zn}, \mathrm{Mg}$, $\mathrm{Ni}$ or $\mathrm{Cu}$ ) (Salgado-Ordorica \& Rappaz, 2008). Unlike the results presented in the section 'Dendrite Growth Directions in Al-Zn Alloys, no DOT was observed for Al-Zn feathery grain specimens as the zinc composition was increased. This is easily understood since such twinned dendrites always grow along $<110>$ directions, regardless of the solute element. Once these structures have nucleated, they seem to be more stable than regular $<100>$ dendrites. Surprisingly, twinned dendrites could only form in the range $10-40 w t \% Z n$. For higher compositions where nontwinned dendrites normally grow along $<110>$ directions (see previous section), no twins could be initiated. The mechanisms for this kinetics growth advantage are still unclear, but further work is being done to better understand growth initiation and stability.

\section{Intra-granular variations of crystallographic orientation in} Al-Zn-Si alloy coatings

$\mathrm{Al}-\mathrm{Zn}-\mathrm{Si}$ coatings deposited on steel sheets by hot dipping exhibit a coarse grain structure with typical grain diameters on the order of a few millimetres. The main microstructural element within each grain is a network of primary $\alpha-\mathrm{Al}$ dendrites. Other present phases are inter-dendritic Si particles 
and $\mathrm{Al}-\mathrm{Zn}(-\mathrm{Si})$ eutectic islands. In the industrial coatings examined in this study, a dendrite arm spacing of about $11 \mu \mathrm{m}$ has been measured. As the coating is only $20 \mu \mathrm{m}$ thick, one or two 'layers' of dendrite arms are present within the coating thickness. In accordance with the observations reported in the section 'Dendrite growth directions in Al-Zn alloys' for binary $\mathrm{Al}-\mathrm{Zn}$ alloys, the dendrite tips in this alloy do not grow along $<100>$ crystallographic directions but along directions in between $<100>$ and $<110>$ directions. In Al$\mathrm{Zn}-\mathrm{Si}$ alloys with $43.4 \mathrm{wt} \% \mathrm{Zn}$, the preferred dendrite growth direction was found to be at $28.5^{\circ}$ from the $<100>$ directions (see Niederberger et al., 2006).

The most remarkable metallurgical feature in $\mathrm{Al}-\mathrm{Zn}-$ $\mathrm{Si}$ alloy coatings is the presence of very pronounced variations of crystallographic orientation within individual grains. This phenomenon has been first reported by Sémoroz et al. (2001), who observed misorientations of up to $35^{\circ}$ within a single grain. These authors interpreted such misorientations as due to either thermal strains induced upon cooling by the differential thermal contraction between steel and $\mathrm{Al}$ or systematic solute gradients developing during growth (zinc and aluminium have different atomic radii). Intra-granular misorientations are also observed in other dendritic solidification microstructures, for example, in $\mathrm{Ni}$ base superalloy single-crystal castings (Napolitano \& Schaefer, 2000). In DS superalloys, misorientations can amount to 5$10^{\circ}$ within one grain. The particularly large misorientations observed in Al-Zn-Si coatings make them an ideal model system for the study of the mechanisms that are responsible for their formation. Hereafter, some selected aspects of the observed intra-granular misorientations are presented.

Detailed EBSD investigations show that the variation of crystallographic orientation within a grain follows distinct patterns of cases closely related to the primary dendrite network. At first sight, one can distinguish three different types of intra-granular misorientations, which are indicated by the encircled zones in Fig. 4(b):

(1) A continuous change of orientation along a dendrite arm as it occurs in many areas in Fig. 4(a) (gradual change from blue to red). In the enlargement shown in Fig. 4(b), zone labelled (1) shows a gradual transition from yellow to orange. Misorientation rates of $4-5^{\circ} \mathrm{mm}^{-1}$ are typically observed in such cases.

(2) Sharp sub-grain boundaries taking their origin in one distinct dendrite arm and propagating into the areas that have subsequently grown from this arm. Three such areas are labelled (2) in Fig. 4(b). One may divide this type of misorientations into two sub-groups. The first one (zone (2a) in Fig. 4(b)) is characterized by small misorientations of less than 2 or $3^{\circ}$. The rotation axis and the sense of rotation of these misorientations are often related to the local dendrite morphology. By contrast, more pronounced misorientations of up to $10^{\circ}$ are sometimes observed. In this case, the misorientation axis is usually not related to the growth morphology. A typical example for the latter case is the sub-grain boundary observed between the blue and the yellow zone near the nucleation centre of the grain (area (2b) in Fig. 4).

(3) Band-like regions that are not directly related to the grain and dendrite structure (zone labelled (3) in Fig. 4(b)).

In none of the three above-mentioned cases, the misorientations are related to the crystallographic orientations of grains in the underlying substrate. Continuous misorientations (type 1) are responsible for a significant part of the misorientations observed in Al-Zn-Si coatings. They are not random in their nature, but the axis of rotation and the sense of rotation are in general related to the dendrite

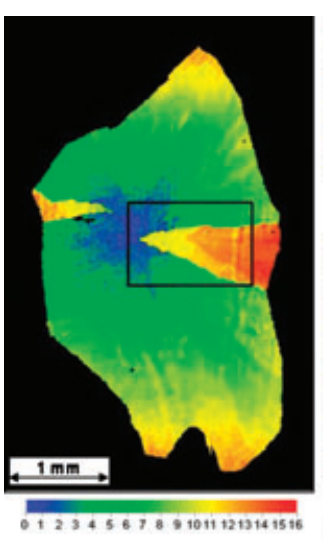

(A)

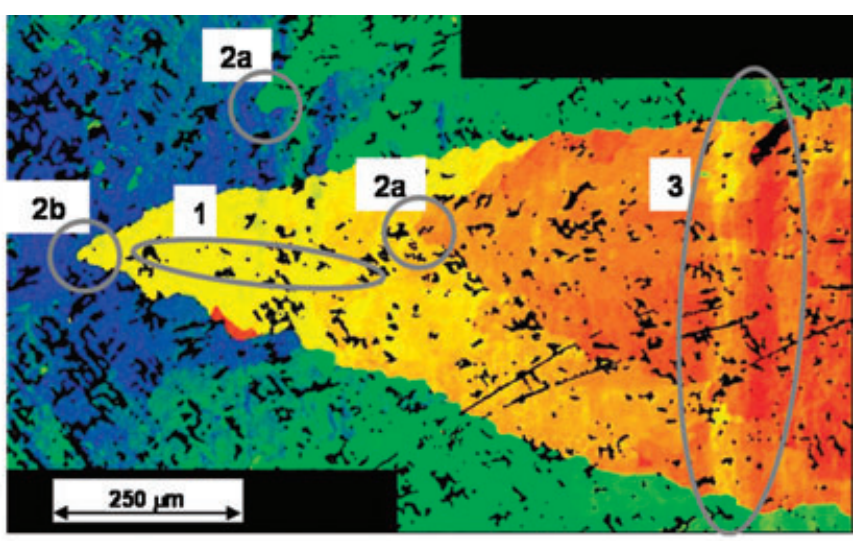

(B)

Fig. 4. (a) EBSD misorientation map of one grain in an Al-Zn-Si coating. (b) On a higher-resolution map, different kinds of misorientations can be observed. The orientation of the nucleus has been chosen as a reference orientation of the misorientation map (blue). Black areas indicate inter-dendritic areas where other phases than $\alpha$-Al are present (Niederberger, 2007). 


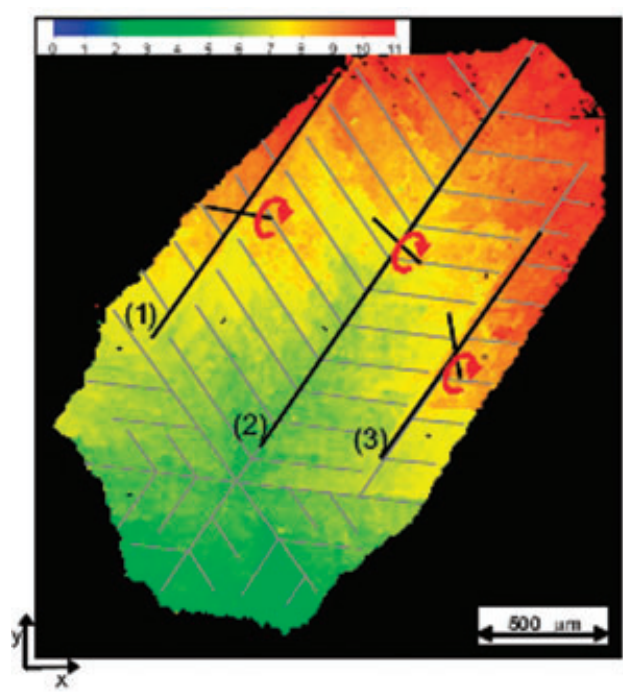

(A)
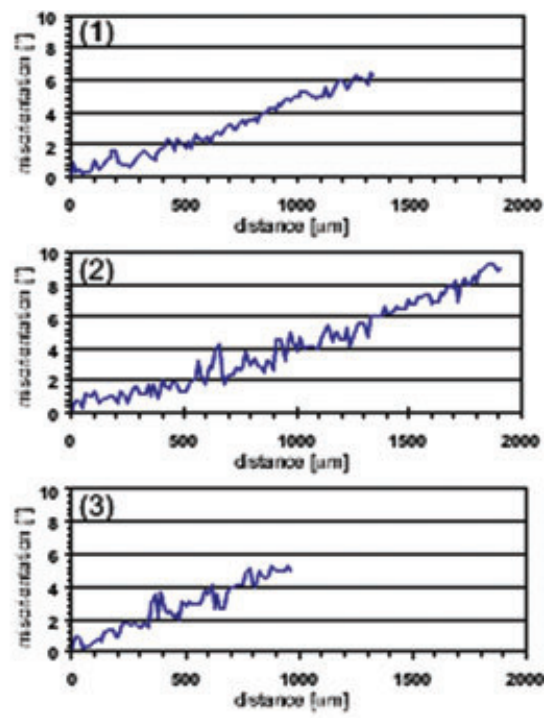

(B)

Fig. 5. (a) EBSD misorientation map of a grain. The predominant dendrite growth directions are schematically given by grey lines. There are three areas in the upper part of the grain that grew from three different but parallel 'pseudo-primary' dendrite arms. The line segments crossing these arms highlighted in black indicate the axis of rotation, the red arrows the sense of rotation along the dendrite arm. (b) The misorientation profiles along these three arms (Niederberger, 2007).

pattern from which they arise. Figure 5(a) shows the EBSD misorientation map of a grain where the predominant growth directions are schematically given by grey lines. The three parallel, long and continuous dendrite arms highlighted with black lines show misorientation-rotation axes that are slightly different. In all three cases, the sense of rotation is oriented towards the steel substrate underneath and the misorientation axis lies approximately in the plane of the coating (i.e. very small rotation component along an axis perpendicular to the surface). For this reason, the rotation axes can easily be represented by the black line segments crossing the examined dendrite arms in Fig. 5(a). When looking at the predominant growth directions that are schematically represented by grey lines in Fig. 5(a), it becomes apparent that the primary dendrite arms (1), (2) and (3) emit secondary branches only towards the left, on both sides and to the right, respectively. These experimental results indicate that the rotation axis does not only depend on the direction of the primary dendrite arm along which the misorientation occurs but also on the presence of secondary arms. It seems that the rotation axis is perpendicular to neither the primary nor the secondary arms but located somewhere in between. Figure 5(b) shows the misorientation profiles along the three primary dendrite arms. Even though the rotation axes are different, the misorientation rates are very similar and in the range of $4-5^{\circ} \mathrm{mm}^{-1}$. These findings were key input to outline a new misorientation mechanism related to capillary forces and solidification shrinkage (Niederberger, 2007).

\section{Grain orientation measurements in galvanized steel sheets}

As for Al-Zn-Si coatings, the solidification of $\mathrm{Zn}-0.2 \mathrm{wt} \% \mathrm{Al}$ coatings is strongly influenced by the fact that the melt is constrained between the steel substrate (in fact the intermetallic formed at the sheet-coating interface) and the free surface in contact with air. These two interfaces offer a high density of heterogeneous nucleation sites, so that grains are principally initiated on the substrate. Microstructures formed in $\mathrm{Zn}-\mathrm{Al}$ under these very peculiar conditions show a strong fibre texture with $<0001>$ normal to the sheet plane (Sémoroz et al., 2002a), but the reasons for such a texture are not yet completely understood. In this respect, EBSD offers a powerful method for the measurement of grain orientation distribution: from EBSD maps, it is possible to reconstruct the population of zinc grains, with their size and Euler angles. An example is given in Fig. 6(a). Histograms of the orientation of the individual grains, constructed from such maps, clearly show the excess number of grains with their $<0001>$ axis normal to the steel sheet (Fig. 6(b)).

Grains nucleating with their $c$ axis perpendicular to the coating surface have the six $<10 \underline{10}\rangle>$ directions parallel to it. Since dendrites in $\mathrm{Zn}-\mathrm{Al}$ grow along these directions with a velocity about twice that of dendrites growing along the $c$ axis, such basal grains occupy a larger surface at the end of solidification. By making histograms of orientation distributions proportional to the number of grains and to their surface (or to the number of measured EBSD points), a growth 

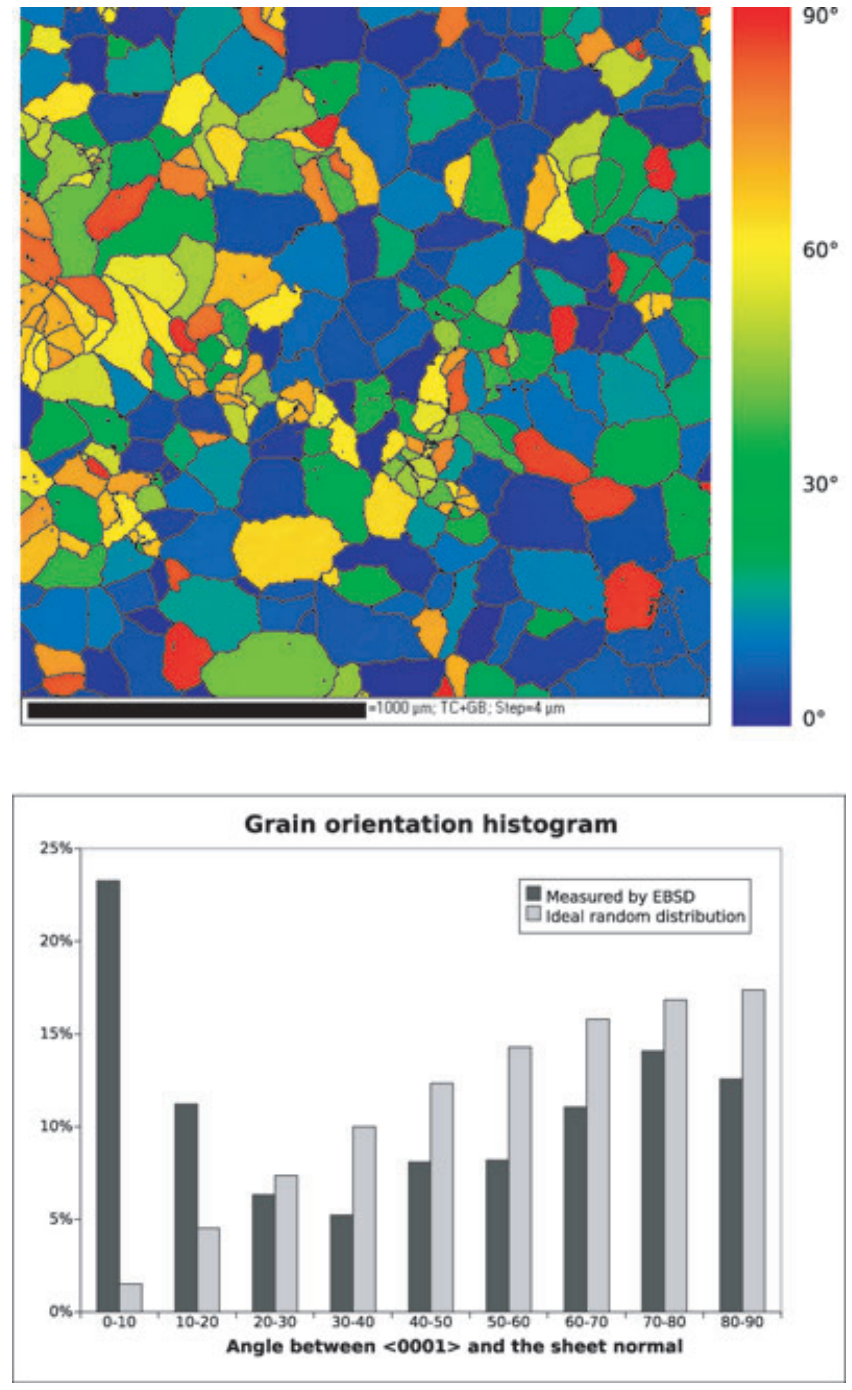

Fig. 6. (a) Fragment of an EBSD map of a hot-dip galvanized coating. The grain boundaries are represented by black lines. The colour gives the texture component as measured at each point: blue means $0^{\circ}$ misorientation between $<0001>$ and the normal to the sheet, red indicates $90^{\circ}$ deviation. (b) Histogram of the grain orientation (averaged over each grain) both measured and computed for a normalised ideal random distribution. A clear discrepancy is visible at low disorientation angles, showing the preferential basal orientation of the grains.

enhancement factor related to the dendrite growth kinetics can be derived (Sémoroz et al., 2002a). Such information is very helpful for accessing the growth kinetics of hexagonal dendrites growing in a confined environment. It is being used in phase-field calculations and in cellular automata to reproduce the experimental findings in an accurate way.

The growth kinetics can partially explain the excess of basal surface, but it cannot account for the high fraction of basal grains: these are formed at nucleation and will not change their orientation anymore. Using well-controlled solidification conditions at various cooling rates, EBSD measurements allow obtaining information on the localization and characteristic under-cooling of nucleation sites.

\section{$\mathrm{Cu}-$ Sn peritectic solidification}

Peritectic alloys are characterized by a $(\ell+\alpha) \rightarrow \beta$ transformation. For compositions in the peritectic range, alloys directionally solidified at large velocities $\left(\approx \mathrm{mm} \mathrm{s}^{-1}\right)$ exhibit $\alpha$ dendrites surrounded by the peritectic $\beta$ phase. At very low solidification speeds, that is, at a speed where planar fronts would normally be expected for individual $\alpha$ or $\beta$ phases, very interesting phenomena and microstructures are found for compositions in the hypoperitectic region (Hunziker et al., 1998). Indeed, in this composition range, none of the planar fronts is stable, and one can observe an alternation of $\alpha$ and $\beta$ regions parallel to the isotherms, that is, the so-called band structure. Depending on the nucleation and growth conditions, one of the phases is not fully developed and islands are observed rather than bands. Thus, these microstructures, characteristic of peritectic alloys, are the result of a complex interplay between nucleation dynamics and growth competition between the primary $\alpha$ and the peritectic $\beta$ phases (Karma et al., 1998; Dobler, 2002; Trivedi \& Park, 2002).

Although lamellar structures have been observed in low solidification interval alloys such as $\mathrm{Fe}-\mathrm{Ni}$ (Dobler et al., 2004) or Ni-Al (Lee \& Verhoeven, 1994), they were revealed only recently in $\mathrm{Cu}-\mathrm{Sn}$ alloys, which exhibit a solidification interval 25 times larger than these previous alloys (Fig. 7). In this system, the $\alpha$ phase has an fcc structure, whereas the crystallographic structure of $\beta$ is bcc but exhibits solid-state transformations (Cortie \& Mavrocordatos, 1991; Liu et al., 2004; Kohler, 2008; Kohler et al., 2008). As can be seen in Fig. 7, $\mathrm{Cu}-\mathrm{Sn}$ alloys exhibit an alternation of $\alpha$ and $\beta$ bands parallel to the isotherms followed by $\alpha$ and $\beta$ lamellae growing in the direction of the thermal gradient as for coupled eutectic

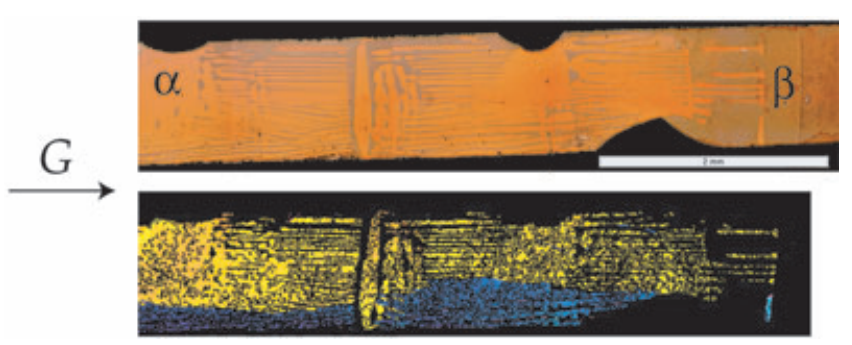

Fig. 7. Optical micrograph of a $\alpha-\beta$ lamellar structure in a $\mathrm{Cu}-21 \mathrm{wt} \% \mathrm{Sn}$ alloy directionally solidified; $G=21 \mathrm{~K} \mathrm{~mm}^{-1}, v=0.58 \mu \mathrm{m} \mathrm{s}^{-1}$, solidification from left to right (top). Corresponding EBSD mapping of the $\alpha$ phase showing that two $\alpha$ grains are present, but bands and lamellae within a grain are continuous (bottom). Thickness of the sample: $1 \mathrm{~mm}$ (Kohler, 2008). 
growth. The bands themselves are not due in this case to a succession of nucleation events, as suggested in previous studies but are more like overlays of one phase covering the other, that is, three-dimensional growth competition between the solid phases. This could be clearly revealed using EBSD measurements of the $\alpha$ phase, as shown in Fig. 7. It should be noted that the $\beta$ phase could be indexed only partially because of solid-state transformations. The $\alpha$ lamellae that originated from these bands have the same crystallographic orientation. These EBSD measurements confirm a mechanism of coupled growth initiation previously revealed by Akamatsu et al. (2001) in organic eutectic systems. During lateral growth of one phase over the other, say $\beta$ over $\alpha$, the speed of the $\beta$ overlay is such that its growth is unstable and gives $\beta$ cells growing parallel to the isotherms. Since the $\alpha$ phase is still growing in between these cells in the direction of the thermal gradient, this leads to coupled growth. In the case of the $\mathrm{Cu}-\mathrm{Sn}$ peritectic system and for positions where the $\beta$ phase did not decompose at solid state, EBSD was also able to reveal that the $\alpha$ and $\beta$ phases were in a Kurdjumov-Sachs relationship, that is, $(111)_{\alpha} / /(110)_{\beta}$ and $<110>_{\alpha} / /<111>_{\beta}$.

\section{Conclusions}

Various examples of applications of EBSD to solidification problems were presented. They showed that combined with optical or electron microscopy imaging, EBSD is a very powerful technique for the characterization of solidification microstructures resulting from nucleation and growth mechanisms. Concerning nucleation, EBSD can reveal the orientation distribution of nuclei heterogeneously formed at a surface, whether it is random or exhibits a texture. For eutectic or peritectic alloys, it also allows a detection of heteroepitaxy relationships between an existing and a newly formed phase. Such information is very helpful in determining local nucleation conditions and mechanisms that prevailed during a given solidification process.

Once nuclei have formed, they grow and compete to produce a final structure made out of columnar and equiaxed grains. EBSD can first reveal unequivocally grain structures in cases where grains are difficult to identify by standard chemical etching and optical microscopy. It is most useful to measure the evolutions of the density and crystallographic texture of columnar grains growing from a random population of grains formed at a surface, thus giving the opportunity to correlating these entities and to shedding light on the dendrite growth competition mechanisms. Local EBSD orientation measurements also give access to dendrite growth directions and to growth defects such as twins in dendrites or in faceted phases. Within individual grains, EBSD has allowed a precise determination of sub-grain misorientations in relationship with the dendritic pattern, thus giving hints on the solidification mechanisms responsible for such misorientations.
So in summary, EBSD has become a characterization tool that provides invaluable insight into mechanisms of nucleation and growth in systems that are otherwise fairly opaque to in situ observations (except for x-ray radiography and tomography on light alloys using synchrotron radiation). As this technique can be coupled with EDX and is being improved by much faster data acquisition, it will provide a unique tool for two-dimensional and three-dimensional analyses (when coupled with focused ion beam) and a deeper understanding of solidification mechanisms.

\section{Acknowledgements}

The authors thank J.-D. Wagnière for BS and DS experiments and the CIME (Interdisciplinary Centre for Electron Microscopy) of EPFL for providing electron microscope facilities. The authors acknowledge the Fonds National Suisse (grant no. 200021-105144), ArcelorMittal (France), Umicore (Belgium), EMPA and European Space Agency (ESA MAP-project AO 98/99-114, ESTEC contract no. $14243 / 00 / \mathrm{NL} / \mathrm{SH}$ ) for funding.

\section{References}

Akamatsu, S., Faivre, G. \& Ihle, T. (1995) Symmetry-broken double fingers and seaweed patterns in thin film directional solidification of a nonfaceted cubic crystal. Phys. Rev. E51, 4751-4773.

Akamatsu, S., Moulinet, S. \& Faivre, G. (2001) The formation of lamellareutectic grains in thin samples. Metall. Mater. Trans. 32A, 2039-2048.

Baba-Kishi, K.Z. (2002) Electron backscatter Kikuchi diffraction in the scanning electron microscope for crystallographic analysis. J. Mater. Sci. 37, 1715-1746.

Burke, E., Broughton, J.Q. \& Gilmer, G.H. (1988) Crystallization of fcc (111) and (100) crystal-melt interfaces: a comparison by molecular dynamics for the Lennard-Jones system. J. Chem. Phys. 89, 1030-1041.

Chalmers, B. (1964) Principles of Solidification. Wiley, New York.

Cortie, M.B. \& Mavrocordatos, C.E. (1991) The decomposition of the betaphase in the copper-tin system. Metall. Mater. Trans. 22A, 11-18.

Dingley, D.J. (2004) Progressive steps in the development of electron backscatter diffraction and orientation imaging microscopy. J. Microsc. 213, 214-224.

Dobler, S. (2002) Directional coupled growth of peritectic alloys. Ph.D. thesis, pp. 1-13. Ecole Polytechnique Fédérale de Lausanne.

Dobler, S., Lo, T.S., Plapp, M., Karma, A. \& Kurz, W. (2004) Peritectic coupled growth. Acta Mater. 52(9), 2795-2808.

Eady, J. \& Hogan, L. (1974) Some crystallographic observations of growthtwinned dendrites in aluminium. J. Cryst. Growth 23(2), 129-136.

Gandin, Ch.-A., Rappaz, M., West, D. \& Adams, B.L. (1995) Grain texture evolution during the columnar growth of dendritic alloys. Metall. Mater. Trans. 26A, 1543-1551.

Gonzales, F. \& Rappaz, M. (2006) Dendrite growth directions in Al-Zn alloys. Metall. Mater. Trans. 37A, 2797-2806.

Gonzales, F. \& Rappaz, M. (2008) Grain selection and texture evolution in directionally solidified Al-Zn alloys. Metall. Mater. Trans. A 39A, 21482160. 
Henry, S. (1999) Etude de la germination et de la croissance maclées dans les alliages d'aluminium. Ph.D. thesis, Ecole Polytechnique Fédérale de Lausanne.

Henry, S., Minghetti, T. \& Rappaz, M. (1998) Dendrite growth morphologies in aluminium alloys. Acta Metal. Mater. 46, 2495-2501.

Henry, S., Gruen, G.-U. \& Rappaz, M. (2004) Influence of convection on feathery grain formation in aluminium alloys. Metall. Mater. Trans. 35A, 2495-2501.

Henry, S., Jarry, P., Jouneau, P.-H. \& Rappaz, M. (1997) Electron backscattered diffraction investigation of the texture of feathery crystals in aluminium alloys. Metall. Mater. Trans. 28A, 207-213.

Hoyt, J. \& Asta, M. (2002) Atomistic computation of liquid diffusivity, solid-liquid interfacial free energy and kinetic coefficient in Au and Ag. Phys. Rev. B65, 214106-214111.

Hunziker, O., Vandyoussefi, M. \& Kurz, W. (1998) Phase and microstructure selection in peritectic alloys close to the limit of constitutional undercooling. Acta Mater. 46(18), 6325-6336.

Karma, A., Rappel, W.J., Fuh, B.C. \& Trivedi, R. (1998) Model of banding in diffusive and convective regimes during directional solidification of peritectic systems. Metall. Mater. Trans. 29A, 1457-1470.

Kerr, H.W. \& Kurz, W. (1996) Solidification of peritectic alloys. Int. Mater. Rev. 41(4), 129-164.

Kohler, F. (2008) Peritectic solidification of Cu-Sn alloys: microstructure competition at low speed. Ph.D. thesis, 4037, EPFL, Switzerland.

Kohler, F., Campanella, T., Nakanishi, S. \& Rappaz, M. (2008) Application of Single Pan Thermal Analysis to $\mathrm{Cu}-\mathrm{Sn}$ peritectic alloys. Acta Mater. 56, 1519-1528.

Lee, J.H. \& Verhoeven, J.D. (1994) Peritectic formation in the Ni-Al system. J. Cryst. Growth 144, 353-366.

Liu, X.J., Wang, C.P., Ohnuma, I., Kainuma, R. \& Ishida, K. (2004)
Experimental investigation and thermodynamic calculation of the phase equilibria in the $\mathrm{Cu}-\mathrm{Sn}$ and $\mathrm{Cu}-\mathrm{Sn}-\mathrm{Mn}$ systems. Metall. Mater. Trans. 35A, 1641-1653.

Napolitano, R.E. \& Schaefer, R.J. (2000) The convergence-fault mechanism for low-angle boundary formation in single-crystal castings. J. Mater. Sci. 35, 1641-1659.

Niederberger, C., Michler, J. \& Jacot, A. (2006) Inverse method for the determination of a mathematical expression for the anisotropy of the solid liquid interfacial energy in Al-Zn-Si alloys. Phys. Rev. E74, 021604 .

Niederberger, C. (2007) Experimental and numerical study of microstructure formation and the origin of crystallographic misorientation in Al-Zn-Si alloy coatings. Ph.D. thesis, 3863, EPFL, Switzerland.

Salgado-Ordorica, M.A. \& Rappaz, M. (2008) Twinned dendrite growth in aluminium alloys. Acta Mater. 56, 5708-5718.

Schwartz, A.J., Kumar, M. \& Adams, B.L. (2000) Electron Backscatter Diffraction in Materials Science. New York, Kluwer Academic/Plenum Publishers.

Sémoroz, A., Durandet, Y. \& Rappaz, M. (2001) EBSD characterization of dendrite growth directions, texture and misorientations of hot-dipped Al-Zn-Si coatings. Acta Mater. 49, 529-541.

Sémoroz, A., Strezov, L. \& Rappaz, M. (2002a) Orientation domains and texture in hot-dipped galvanized coatings. Metall. Mater. Trans. 33A, 2695-2701.

Sémoroz, A., Strezov, L. \& Rappaz, M. (2002b) Numerical simulation of Zn coating solidification. Metall. Mater. Trans. 33A, 2685-2694.

Trivedi, R. \& Park, J.S. (2002) Dynamics of microstructure formation in the two phase region of peritectic systems. J. Cryst. Growth 235, 572588. 